\title{
Estimating cost of using a rotation system when operating in rigorous climate regions
}

\author{
Anna Minnullina ${ }^{1, *}$, and Alla Larkina $^{2}$ \\ ${ }^{1}$ Tyumen Industrial University, Volodarskogo St., 38, Tyumen, 625000, Russia \\ ${ }^{2}$ Samara State Technical University, Molodogvardeyskaya St., 194, Samara, 443100, Russia
}

\begin{abstract}
Basic cost estimation techniques concerning the use of a rotation system in operation consider particular characteristics of rigorous climate regions. By means of the offered recommendations the following indicators are defined: an average number of workers for operation; an amount of salary supplements; standard working hours for personnel on rotating assignments; equipment relocation costs, rotation camp maintenance and rotation worker transportation costs. In the situation when a building contractor has to prove camp accomplishment costs in details most road builders face the difficulties in cost sheet formation. The offered technique of cost estimation is approved at the road section being influenced by Arctic Extremes and confirmed its operational flexibility.
\end{abstract}

\section{Introduction}

One of the possible ways to increase the efficiency of road-building company operation is to employ various production methods and techniques of building and installation works. Currently, building company mobility, which means their readiness to perform on-site works far away from the sites of permanent deployment, is of a particular importance. Therefore, the enterprises widely use the rotation system when organizing road construction works that allows to reduce the construction period if compared to other options.

Besides, mobility is becoming more a survival condition for building companies as the modern market conditions more radically set a task for them to seek for new customers and project sites, including outside the usual area of activity. Therefore, a rotation system when organizing construction works is more intensively used by the enterprises. However, the use of a rotation system results in the need to compensate the expenses incurred by the contractor. The complexity of the calculation is that currently there is no technique to introduce a rotation system in road-building operation. There are technique to employ a rotation system when carrying out geological, oil-field and gas producing works, but they don't consider peculiarities of road-building industry. Elimination of this shortcoming results in the need to develop a rotation system technique in road-building operation [1].

A rotation system is also used to reduce the construction period for industrial and social purpose projects in undeveloped, remote areas and in areas with high work pace in case of the lack of the required human resources in this area [1-3].

\footnotetext{
* Corresponding author: minnullinaay@yandex.ru
} 
The organization for rotation system operation has to provide on-site technological process rhythm, continuity and complexity, observance of labour protection, operation, technical and machine maintenance rules, valuable property safety, and administrative, technical and economic management continuity.

The use of a rotation system is due to the need to compensate the expenses incurred by the contractor. The complexity of the calculation is that currently a rotation system technique is poorly developed in road-building operation in rigorous climate regions. There are technique to employ a rotation system when carrying out geological, oil-field and gas producing works, but they don't consider peculiarities of road-building industry.

\section{Methods}

According to the authors, when introducing a rotation labour system in road-building operation, the difficulties are caused by:

- calculation of the average number of workers;

- calculation of an amount of salary supplements;

- setting standard working hours for personnel on rotating assignments;

- calculation of equipment relocation costs;

- calculation of rotation camp maintenance costs;

- calculation of rotation worker transportation costs;

- logistic assistance.

In this regard, the following recommendations on allocation of these costs when operating in the remote sites in rigorous climate regions are offered [4-6, 8-15].

1. Calculation of the average number of workers on rotating assignments.

The average number of workers on rotating assignments $\left(W_{r}\right)$ of any category is defined by the number of workers on site $(W)$ and on a rotational leave $\left(W_{l}\right)$ :

$$
W_{r}=W+W_{l}
$$

The average number of workers on site $(\mathrm{W})$ is determined from the formula:

$$
W=\frac{V_{I C W}}{B_{h} T_{h} K_{\text {exc }}}
$$

$V_{I C W}$ is a site construction spread; $\mathrm{B}_{h}$ is standard working hours per a worker at a standard operational method; $\mathrm{T}_{\mathrm{h}}$ is operational duration at a standard operational method; $K_{\text {exc }}-$ excess hours coefficient [60].

The average number of rotational linear engineering personnel can be determined based on the number of rotational workers [81], or by their ratio in the total number of workers.

The number of workers of all types being on a rotational leave, $W_{l}$ determined by the number of the workers on site, $W$, and excess hours coefficient $K_{\text {exc }}$ :

$$
W_{l}=W \times\left(K_{\text {exc }}-1\right)
$$

When using a rotation system in construction management, integrated and functional teams with their obligatory dividing into structural or technological groups can be used that will allow to organize proper rotational worker removability, to ensure continuity and rhythm in building operation.

2. Calculation of an amount of salary supplements when performing road-building works on a rational base.

Compensation for employees working on a rotational base in building operation is made based on the existing rules of labor input standards and building and installation work quotations. Locality pay factors, coefficients for absence of human life, water, high mountain 
areas that exist for employees of relevant organizations in operation sites are applied to rotational worker salaries.

Rotational workers are due for additional payments in case of: excess working hours when there is a record of cumulative hours worked; working mobility; the time spent travelling from the building company dislocation site to the project under construction and back. At the same time, the overtime work due to the long hours isn't additionally paid.

When planning, the amount of salary supplements for excess working hours over standard working hours $C_{\text {st.w }}$ can be determined by the formula:

$$
C_{s t . w}=W_{r} T_{r} P_{a v}\left(K_{e x c}-1\right)
$$

$P_{a v}$ is daily average salary per a worker.

With their consent, rotational workers resigned before the end of the accounting period can have the resignation date determined considering the days scheduled for leave (compensatory leave) due to overwork compared to standard working hours. These days are paid the same way as the additional days for leave (compensatory leaves) provided during the employment at the company.

$75 \%$ of a monthly base wage rate, a fixed official salary is paid in rigorous climate regions. Travel hours taking not more than two days per a trip to the work place and back are paid based on a base wage rate or salaries assuming a 7-hour working day. The specified time isn't included in standard working hours.

An amount of salary supplements for the time rotational workers spend traveling $C_{t r . w}$ is determined by the formula:

$$
C_{t r . w}=2 W_{r} T_{r} P_{a v} \frac{D_{t r}}{T_{r c}}
$$

$D_{t r}$ is duration of rotational worker transportation, days., $T_{r c}-$ duration of a rotational cycle, days.

Rotational employees working for building companies and constantly working in rigorous climate regions are granted with salary supplements and additional leaves in accordance with the terms provided to people permanently working in the specified areas. Days of staying in the Far North regions and equivalent areas and travel time, but no more than two days per a trip to the work place and back are included in the employment history granting the right to salary supplements and an additional leave.

Expenses for Northern allowance payment, locality pay factor and payment for rest days between rotation shifts are undertaken within the company wages funds calculated according to the standard norms. Expenses for salary supplements due to a rotational method of operation, travel time payment and delays during travels are undertaken within the estimates and costs of works and services.

To additionally motivate the employees working on a rotational basis building companies should provide additional social fringe benefits to them: top-priority provision of housing, vouchers for vacation centers, places in kindergartens and day nurseries, shorter working days for their wives, speciality goods sales, etc. It is also recommended to make use of experience of building companies which provide a $10-15 \%$ supplement increase to rotational workers following the year progress in comparison with those working in normal conditions.

3. Setting standard working hours for personnel on rotating assignments.

The rotational work and rest schedule for workers is defined by a rotational cycle including rotation duration and rotational change (daily work), inter-shift work and rest schedule, inter-shift, rotational and interrotational rest [7]. 
Rotational shift lasting over 8 but not more than 10 hours is set by managerial decision of a building company in coordination with a trade union committee, while from 10 to 12 hours - with the permission of the ministry and department in coordination with the Central trade union committee. Increase in shift duration up to $10-12$ hours isn't allowed when there are shortened working hours established due to operating under harmful labour conditions.

Inter-shift rest duration for rotational workers regarding any shift duration shouldn't be less than 12 hours.

Rotational shift duration is determined by the formula:

$$
K_{\text {exc }}=\frac{T_{\text {act }}}{T_{\text {stand }}}
$$

$T_{\text {act }}$ is hours actually worked over a week; $T_{\text {stand }}$ is standard rotational shift duration $\left(T_{\text {stand }}\right.$ $=41$ hours since operation is carried out in severe climatic conditions).

Excess hours coefficient values at a 9-12-hour shift over a six-day working week are given in Table 1.

For a particular site, the optimum value of excess hours coefficient $K_{\text {exc }}^{\text {opt }}$ providing the maximum cost advantages due to introduction of a rotation system is offered to determine by the modified traditional model:

$$
K_{\text {exc }}^{\text {opt }}=\sqrt{\frac{B\left(K_{\text {exp }}+q K_{f} K_{t}\right)+Z_{c}}{P_{a v}}}
$$

$B$ is an average work performance by an employee, rub /pax.-days.; $K_{\text {exp }}$ is a coefficient defining a ratio of conditional-constant expenses in installation and construction works; $q$ is a weighted average capital price of the road-building company (theoretically given expenses considered as a standard industry efficiency $\mathrm{EH}) ; K_{f}$ is a coefficient considering a ratio of installation and construction works in the total costs of the invested capital stock; $K_{t}$ is a coefficient considering the ratio of standard object construction duration estimated in days to the number of working days over a year; $Z_{c}$ is rotational camp creation and maintenance costs per one rotational worker a day, the rub/pax - day; $P_{a v}$ is a daily average salary of a worker estimated based on the base wages rate or salary, rub/ pax - day.

Table 1. Coefficient value of excess hours.

\begin{tabular}{|c|c|c|c|}
\hline $\mathrm{N}_{0}$ & Working hours, hrs & Working hours a week, $T_{\text {act }}$ & Excess hours coefficient, $K_{\text {exc }}$ \\
\hline 1 & 8.2 & 41 & 1 \\
\hline 2 & 9 & 54 & 1.317 \\
\hline 3 & 10 & 60 & 1.463 \\
\hline 4 & 11 & 66 & 1.610 \\
\hline 5 & 12 & 72 & 1.756 \\
\hline
\end{tabular}

The coefficient defining a ratio of conditional and constant expenses in installation and construction works is calculated by the formula:

$$
K_{\text {exp }}=\frac{0.5 H_{z}}{1.06\left(100-H_{z}\right)}+\frac{0.15 H_{\text {mech.op }}}{1.06\left(100-H_{\text {mech.op }}\right)}+\frac{0.01 H_{\text {mat }}}{1.06\left(100-H_{\text {mat }}\right)}
$$

$H_{z}, H_{\text {mech.op }}, H_{\text {mat }}$ is a ratio, \%, of the expenses on the expenditure side of overhead expenses, car and mechanism operation and material costs respectively accepted in the company planned operation cost; $0.5 ; 0.15 ; 0.01$ are coefficients considering a ratio of conditional and constant expenses on the relevant expenditure side; 1.06 is a coefficient considering the amount of planned accumulation in the estimated cost of an object. 
Conditional and constants expenses are the expenses not depending on the scope of performed works (administrative, building site improvement, fire and watchman service maintenance, etc.). To get approximate calculations, one can assume their measure assessed at $50 \%$ of overhead costs, at $15 \%$ of machine operation cost, at $1 \%$ of material costs.

The coefficient considering a ratio of installation and construction works in the invested capital stock is determined by the formula:

$$
K_{f}=\frac{F}{V}
$$

$F$ is the cost of a capital stock put into operation assumed according to the itemized list, RUB, in thousands.; $V$ is the scope of installation and construction works, RUB, in thousands.

The average salary of a worker is determined by the formula:

$$
P_{a v}=\sum_{i=1}^{6} K_{r w i} T_{c m i}+\sum_{j=1}^{n} K_{r w j} P_{a v j}
$$

$K_{r w i}$ is a coefficient considering a ratio of $i$-class rotational workers; $T_{c m i}$ is a daily wages rate of an $i$-class worker, rub/pax - day; $K_{r w j}$ is a coefficient considering a ratio of $j$-salary rotational workers (is determined by actual data); $P_{a v j}$ is a daily average salary of a j-salary worker. Increase in shift duration when organizing construction operation on rotational basis leads to decrease in workers' hourly average labor productivity. The extent of its decrease is established by standard research stations of building companies based on the working day photos.

To get rough calculations, average coefficients of decrease in hourly average labor productivity of rotational workers can be used, based on domestic [5] and foreign researches:

- at a 9-hour shift - 0.02-0.04;

- at a 10-hour shift - 0.04-0.06;

- at a 11-hour shift - 0.06-0.08;

- at a 12-hour shift - 0.08-0.12.

Increase in rotation shift duration and decrease in hour labor productivity of rotational workers cause changes in a project construction period, which is determined by the formula:

$$
T_{p c p}=\frac{T_{\text {stand }}}{K_{\text {exc }}\left(1-K_{\text {dec.w }}\right)}
$$

$T_{p c p}$ is a project construction period when construction is organized on rotational basis, days; $T_{\text {stand }}$ is a standard project construction period, days; $K_{\text {dec.w }}$ is a coefficient of decrease in work performance due to the increase in shift duration.

When construction is organized on rotational basis, working hours and rest time for employees are regulated by shift schedules which have to consider operation period and technology. They are developed on the basis of annual crew plans and crew rotation schedules among the projects.

4. Calculation of equipment relocation costs in a rotation camp.

Relocation costs can be determined by the formula:

$$
Z_{\text {exc }}=Z_{p r}+Z_{t r}+Z_{a v}+Z_{\text {rel.p }}
$$

$Z_{p r}$ is material handling costs; $Z_{t r}$ is equipment transportation costs (module buildings, power plant, etc.); $Z_{a v}$ is a salary of staff maintaining relocation, including supplements and traveling allowances; $Z_{\text {rel.p }}$ is depreciation expenses for the relocated property.

5. Maintenance costs calculation of a complex rotation camp. 
Rotation camps are a complex of residential, cultural and social, sanitary and economic buildings and constructions designed to support life of the employees working on a rotational basis during the period of their rest at the rotation site, to support construction, specialpurpose machinery and motor transport service, inventory stock storage.

Costs for rotation camp creation and operation Св.п are determined by the formula:

$$
C_{c}=W T_{p c p} Z_{c}
$$

$W$ is the number of workers on site; $T_{p c p}$ is a project construction period when construction is organized on the rotational basis, days $Z_{c}$ is costs for rotation camp creation and operation per a worker on site, rub/pax - days:

$$
Z_{c}=1.05 K_{\text {serv }} A\left(\frac{C_{b}}{K_{\text {ret }} T_{\text {stand }}}+\frac{C_{\text {sq.m }}}{T_{\text {stand }}}+C_{\text {op }}\right)
$$

1.05 is a coefficient considering contract worker in the rotation camp; $K_{\text {serv }}$ is a coefficient considering the number of service personnel, defining the ratio of the number of workers on site to the number of service personnel; $A$ is a standard building area of a rotation camp per a person, sq.m/pax; $C_{b}$ is a cost for 1 sq.m of mobile buildings, rub/sq.m; $C_{s q . m}$ is a cost for mobile building construction per 1 sq.m of their area, rub/sq.m; $C_{o p}$ is operational expenses per 1 sq.m of mobile buildings per day, rub; $K_{r e t}$ is a coefficient of mobile building returns.

Buildings area standards for a rotation camp are provided in Table 2.

Table 2. Standard area indices for mobile building.

\begin{tabular}{|c|l|c|}
\hline N0 & \multicolumn{1}{|c|}{ Building titles } & Standard area, sq.m./pax \\
\hline 1 & Family house & 9 \\
\hline 2 & Hostel & 6 \\
\hline 3 & Food shop & 0.039 \\
\hline 4 & Steam bath & 0.116 \\
\hline 5 & Laundry & 0.044 \\
\hline 6 & Service center & 0.251 \\
\hline 7 & Health isolation center & 0.089 \\
\hline 8 & Canteen & 1.02 \\
\hline
\end{tabular}

A special emphasis when calculating the costs of a rotation operation system should be laid upon the costs for rotational employee medical support.

6. Calculation of rotation worker transportation costs.

To make preliminary estimations, transportation costs of rotational employees are determined by the formula:

$$
C_{t r}=\frac{2 W_{r} T_{r} Z_{t r}}{T_{d}}
$$

where $W_{r}$ is the number of rotational employees;

$T_{r}$ is a rotational period of a project construction, days;

$Z_{t r}$ is the one-way transportation cost per a person a day, rub/pax - days;

$T_{d}$ is a rotational cycle duration, days.

The transportation cost of one worker $Z_{t r}$ is assumed based on the planned and estimated prices or rates for passenger transportation.

Thus, the authors considered basic provisions accountable when introducing a rotation system in road-building operation. Based on the given method of a rotation system use in road-building operation, actual contractor expenses will be further calculated when operating with the use of the given method for the project owner to compensate operation. 


\section{Assessment and Results}

Efficiency assessment of a rotation method in road-building operation based on the suggested technique has been carried out on the example of the Tyumen - Khanty-Mansiysk highway reconstruction going through Tobolsk, Surgut, Nefteyugansk, the Tyumen- KhMAD border road section, km range 345-384 (an approach road to Turtas).

A rotational camp construction is required for the project due to impossibility of daily transportation (time expenditure for traveling takes more than 3 hours) of road construction company employees from the operation site to the permanent residence and back.

To design a standard project of a rotational camp, calculation of the expenses offered by the authors is required to be carried out.

1. Calculation of the average number of workers:

1) $102709970 \mathrm{rub} / 2$ years $=51354985 \mathrm{rub}$ - the annual scope of highway construction at 2018 values;

2) $51354985 \mathrm{rub} / 521630 \mathrm{rub}=98$ people - the average annual number of workers required to develop the volumes of construction set by designing estimates for highway construction in one-shift operation;

3) 98 people / 2 shifts $=49$ people - the average annual number of workers required to develop the volumes of construction set by designing estimates for highway construction in two-shift operation;

Thus, the average number of the workers living in a rotation is to be 49 people. In addition, two foremen and a supervising foreman are involved in construction operation.

Thus, 52 persons are constantly required to work at the Tyumen - Khanty-Mansiysk highway reconstruction.

2. Calculation of allowances for a rotation based work is presented in Table 3.

Table 3. Calculation of allowances for a rotation based work.

\begin{tabular}{|l|c|}
\hline \multicolumn{1}{|c|}{ Indicator } & Value, rub. \\
\hline On-site monthly rate & 2130 \\
\hline Salary supplement for a rotation based work & 185310 \\
\hline $\begin{array}{l}\text { Salary supplement for continuity of employment at the enterprises located in the } \\
\text { high north areas }\end{array}$ & 24708 \\
\hline Total salary supplement for a rotation based work & 210018 \\
\hline
\end{tabular}

3. Calculation of costs for employee transportation to the operation site and back is presented in Table 4.

Table 4. Calculation of costs for employee transportation to the operation site and back.

\begin{tabular}{|l|c|}
\hline \multicolumn{1}{|c|}{ Routes } & Value, rub. \\
\hline $\begin{array}{l}\text { 1. Employee transportation from Utyashevo industrial base to the Tavda railway } \\
\text { station }\end{array}$ & 9613 \\
\hline 2. Employee transportation from the Tavda railway station to the Mortka station & 5568 \\
\hline $\begin{array}{l}\text { 3. Employee transportation from the Mortka station to the rotation camp is } \\
\text { carried out by two Urals-Vahta cars }\end{array}$ & 406 \\
\hline Total cost of employee transportation to the rotation camp for one rotation team & 15587 \\
\hline $\begin{array}{l}\text { The return employee transportation from the rotation camp to the industrial base } \\
\text { in Utyashevo }\end{array}$ & 15587 \\
\hline $\begin{array}{l}\text { Total amount of costs of employee transportation from the industrial base to the } \\
\text { rotation camp and back two times a month }\end{array}$ & 62348 \\
\hline
\end{tabular}

4. Calculation of expenses for residential building maintenance is presented in Table 5. 
Table 5. Calculation of expenses for residential building maintenance.

\begin{tabular}{|l|c|}
\hline \multicolumn{1}{|c|}{ Expenditures } & Value, rub. / mth. \\
\hline $\begin{array}{l}\text { Expenses for module building and fuel storage tank delivery to the rotation } \\
\text { camp from Roshchino industrial base }\end{array}$ & 7375 \\
\hline $\begin{array}{l}\text { Standard depreciations for dwelling and utility rooms according to the } \\
\text { manufacturer data and depreciation norms }\end{array}$ & 52189 \\
\hline Expenses for technical services and maintenance & 10438 \\
\hline Total expenses for residential building maintenance & 62627 \\
\hline
\end{tabular}

Summary settlement of total monthly expenses for a rotation camp maintenance is presented in Table 6 .

Table 6. Summary settlement of total monthly expenses for a rotation camp maintenance.

\begin{tabular}{|l|c|}
\hline \multicolumn{1}{|c|}{ Expenditures } & Value, rub. / mth. \\
\hline Supplements for employees working on a rotational basis & 210018 \\
\hline Employee transportation to the site and back & 62348 \\
\hline Expenses for the rotational camp maintenance & 71250 \\
\hline Expenses for water delivery to the rotation camp & 14601 \\
\hline Expenses for rotation camp power supply & 31181 \\
\hline Expenses for medical care services & 18626 \\
\hline Expenses for rotational camp installation and provision of amenities & 89760 \\
\hline Total monthly expenses for a rotation camp maintenance & 497784 \\
\hline
\end{tabular}

Thus, expenses for the whole construction period will make:

24 months $\times 497784 \mathrm{rub}=11946816$ rub.

The owner must compensate these expenses to the contractor. However, according to the author, before showing the actual expenses calculation to the owner, it is required to prove the efficiency of a rotation system application in road-building operation.

\section{Conclusions}

The efficiency of a rotation system application in construction management is shown in the social sphere and economic results.

The social effect of a rotation system application is in providing normal working conditions, rest and life for workers and members of their families in specific conditions of the dispersed construction and under extreme operation conditions. It allows refusal of workers' frequent change of residence and the undesired settlement of their families in unhealthy climatic zones, having reduced builders' stay time there and having provided them permanent comfortable housing and desired social service, to employ working family members.

Reduced time of stay in the areas with unhealthy climatic conditions, numbers of transportations and provision of the necessary cultural and social services for the workers in rotation camps promotes their health maintenance. In case a rotation system application is provided in a project construction management and its estimated cost, the economic effect due to this method introduction is shown at the national economy level through the indicators of a capital investment use. In case a rotation system application isn't provided by design estimate documentation, and its introduction is carried out on an initiative and at the expense of a building company, the economic effect is shown at the self-supporting level through the change in profits of the introducing company. 


\section{References}

1. VNIPI labor in construction (1984)

2. G.A. Vasilieva, The accounting bulletin 1, 53-56 (2000)

3. M.I. Veizman, V.A. Bochin, Directory of the road engineer (1980)

4. V.V. Kovalev, Methods for evaluating investment projects (2010)

5. V.V. Kovalev, Vit.V. Kovalev, Finance of enterprises (2016)

6. G.A. Savickaya, Analysis of the economic activity of the enterprise (2017)

7. M. Volodina, T. Rocheluk, Yu. Coi, Car roads 9, 45 (2002)

8. V.V. Gasilov, M. Kalinin, Russian traveler 33, 91 (2002)

9. V.A. Grunschtam, Remuneration of labor in construction (2016)

10. V.R. Dorochkin, The system of pricing in construction (2015)

11. A. Minnullina, V. Vasiliev, E3S Web of Conferences 33, 03060 (2018) https://doi.org/10.1051/e3sconf/20183303060

12. A. Minnullina, R. Abdrazakov, IOP Conference Series: Earth and Environmental Science 90(1), 012089 (2017) DOI: 10.1088/1755-1315/90/1/012089

13. A. Minnullina, R. Abdrazakov, Advances in Intelligent Systems and Computing 692, 1224-1233 (2018) DOI: 10.1007/978-3-319-70987-1_131

14. A.V. Kopytova, Exchange of intellectual property 3 (XIV), 31-37 (2015)

15. A. Minnullina, MATEC Web of Conferences 106, 08067 (2017) DOI: 10.1051/matecconf/201710608067 